\title{
Acs Approval Of Chemistry Degree Programs: Benefits And Pitfalls
}

\section{Marjorie Caserio}

Marjorie C Caserio, "Acs Approval Of Chemistry Degree Programs: Benefits And Pitfalls," Proc. SPIE 0978, 1988 Intl Conf on Education in Optics, (27 April 1989); doi: 10.1117/12.948604

Event: 32nd Annual International Technical Symposium on Optical and United States 


\title{
ACS Approval of Chemistry Degree Programs: Benefits and Pitfalls
}

\author{
Marjorie C. Caserio \\ Department of Chemistry \\ University of California, Irvine, California 92717 \\ Member, American Chemical Society Committee on Professional Training
}

\begin{abstract}
The influence of a professional society on education at the undergraduate level is illustrated for the discipline of chemistry.

\section{INTRODUCTION}

It may be asked - what possible relevance has approval of chemistry degree programs to an international conference on critical issues facing optics education? The reply is simply that, whatever the discipline, the primary objective of an approval/certification process is to help improve the quality of education. Although the focus of this paper is on issues facing chemistry education, similar issues are almost certainly pertinent to optics education.
\end{abstract}

I begin with a few key facts about the American Chemical Society (ACS) and its Committee on Professional Training (CPT), which is the committee authorized by the Society to develop and maintain a program of approval of undergraduate degree programs in chemistry at four-year colleges and universities across the nation. Because it is of interest to understand how the program evolved, a few historical facts are in order. I will then review the program's current status, the benefits that have accrued and the problems that exist. Let me stress the positive aspects of problems, because the problems, and efforts to solve them, drive the program forward.

\section{WHAT IS THE ACS-CPT AND WHAT DOES IT DO?}

The American Chemical Society is a venerable professional society (founded in1876) that currently has about 138,000 chemists and chemical engineers as members, $60 \%$ of whom are employed in industry, $25 \%$ by academic institutions, and $15 \%$ by other types of employers. The Committee on Professional Training (CPT) was established by the Society in 1936, during the depression years, to study the training of professional chemists in the hope that better training would provide more jobs. The Committee's main objective remains as it always has - to encourage and help schools provide quality education. It does so by establishing guidelines and setting minimum standards of education in chemistry at the undergraduate level, and in approving schools (at their request) offering degree programs that meet or exceed these standards. In turn, ACS-approved schools may certify their graduates who successfully complete the ACS-approved program.

As a result of the Committee's work, there are today 584 colleges and universities in the United States with ACS approved chemistry degree programs. In 1987, these schools produced 8,838 graduates, or $92 \%$ of the nation's undergraduate chemistry majors, although only 3,663 or $42 \%$ of these majors are certified as having completed the ACS-approved program. These same schools in 1987 produced 1,626 MA graduates and 1,936 Ph.D. graduates in chemistry.

In the initial years and into the 1950's, the Committee's work was directed mostly towards setting criteria for quality chemistry programs and evaluating requests from schools for ACS-approval of their programs. For the purpose of maintaining quality, each approved program is reviewed carefully at five-year 
intervals. In fact, the Committee's work in recent years has dealt more with the five-year reviews of approved schools than with new applications for approval. The quest for the best educational program through constant efforts to improve the curriculum continues to be a major undertaking, as it was when ACS-CPT was first conceived.

\section{MEMBERSHIP AND THE APPROVAL PROCESS}

The members of ACS-CPT (twelve in number) are experienced scientists and educators chosen to represent, as far as possible, the different fields of the discipline, different professional objectives, and a mix of public and private educational institutions, large and small. Each is appointed for a three-year term which may be renewed no more than twice. The committee is assisted by a permanent professional staff, and by consultants, who are appointed to provide needed expertise and continuity. Most importantly, there are currently 140 professional associates who visit colleges and universities upon invitation and report to ACS-CPT on the quality of chemistry programs, their strengths and weaknesses.

An important point is that the American Chemical Society approves an educational program but does not accredit either a program or an institution. From the start, ACS-CPT sought to avoid rigorous program definition often attributed to accreditation by professional organizations. Its function is to offer guidelines, issue minimum standards, and to counsel departments. Emphasis has been on determining whether a Department meets established criteria of quality education.

The expense of administering the ACS-approved degree program is substantial, yet the expense is born entirely by the Society. The approval process is always initiated by the school, and site visits are never made without explicit invitation from the President or Chancellor of the institution. This is to ensure that the Society does not impose educational objectives on an institution, and that its influence on education be sought freely and without obligation.

\section{CRITERIA OF QUALITY}

What are the criteria for a quality program? A review of a department's program includes a detailed look at the curriculum. Other indicators are the number of faculty and their degree qualifications, the areas of expertise or composition of the faculty, evidence of their professional activites, creative scholarship or research, teaching loads, compensation, and opportunities for professional advancement such as sabbatical leave policies. In addition, the physical facilities, instrumentation, library collection, staff support, extramural suppport, operating budgets and administrative structure are all indicative of the health and strength of a department. The number of majors in the program and the success of its graduates over time are also excellent indicators of quality, and statistical information on the placement of graduates is normally requested.

\section{WHAT ARE THE BENEFITS?}

There is little doubt that the ACS-CPT approval process and guidelines for undergraduate education have played a major role over the years in improving the quality of chemical education in the United States. Few other disciplines in the typical college of arts and sciences have such well-developed national criteria for quality. The ACS-CPT has fostered continual interchange with departments, practising chemists, industrial and research organizations, in an effort to measure the pulse of science and respond to changing needs. The importance attached by the committee to adequate facilities, safe facilities, up-to-date equipment, resources, realistic teaching loads, and so on, have had a profoundly positive impact on many, many schools, particularly schools with Administrations reluctant to provide needed funding. The support a professional society can give to a department seeking to convince its administrative leadership of the need for resources can be powerfully persuasive. Ultimately, the students benefit, and so does the profession and the nation. 


\section{WHAT ARE THE PITFALLS?}

There are numerous pitfalls or detractions in the approval of degree programs. I will try to identify the most important ones. First, the range of approved schools varies widely. There are small schools with the minimum number of faculty (4); and there are large research universities; but the same guidelines apply irrespective of school size and whether or not there is a graduate program. Undeniably, the prestigious research universities in the nation establish the hallmark in education and, for more than fifty years, the ACS-CPT has attempted to explicate their standards to the larger educational community. It is, therefore, somewhat ironic that some of these very prestigious schools regard the ACS-approval program as superfluous. Moreover, some truly excellent departments do not choose to certify their graduates upon completion of the baccalaureate degree even when the students have undoubtedly completed an approved program. Others even express their intent to withdraw from the list of approved schools. The reasons are varied, but they include a degree of impatience with the paperwork involved, an attitude that "our graduates don't need it," and a perception that an ACS-CPT approved program is too prescriptive, inflexible, and incompatible with their own majors program. We will all lose if this attitude prevails. If the top research universities should withdraw from the program, the losers will be the many schools who are motivated by and take pride in the fact that they rank with these universities as having an ACS-approved chemistry program. It would send an unintended message of disregard for standards to the educational community. A further consideration is that any institution, however prestigious, that is unwilling to accept external review or consider alternative approaches to education will suffer (osteoporosis) in the long run.

Regarding the curriculum,throughout its existence ACS-CPT has striven to set curricular guidelines rather than course content. It has set minimum standards laced with recommendations - but not with requirements. It has identified the core areas of the discipline, and emphasized the essential nature of the experimental approach through laboratory instruction. It has steadfastly refused to prescribe a curriculum, or advise on textbooks. Its objective has been to offer an educational framework which departments could build on or adapt to their needs and objectives. Certainly, there is no single curriculum that must be adopted. However, CPT's published guidelines have received many different interpretations from the institutions it seeks to serve. Some consider them too vague and openly request more specific guidance on what topics and how much of each to teach. The more common reaction, however, is to interpret the guidelines as rules. CPT is then seen as an enforcer. Such an interpretation leads to accusations of mandated curricula, unnecessary uniformity, over organization, stifling of innovation, and impedance of change. It is exceedingly difficult for a professional organization to advise on educational standards in a manner that is helpful, not overly specific, nor unduly bland, and which at the same time encourages innovation and stimulates curricular reform.

I have already mentioned that curricular guidelines are developed as the result of extensive consultation with educators, professional chemists and scientists. It will come as no surprise that, if all the recommendations received by ACS-CPTwere in fact implemented, the curriculum would be so full that no undergraduate would graduate until middle life. The growth in knowledge, the explosion of information, and the erosion of interdisciplinary boundaries are exciting and marvellous, but this progress has made it increasingly difficult to contain a professional degree program within reasonable limits. By way of example, the importance of chemistry in molecular biology underscores the need to include biochemistry in the undergraduate program. The overlap between physics and chemistry is evident in the advances made in solid state physics, the development of new electronic materials and semiconductors. Thus the cry goes out to educate students in the chemistry of new materials. Industry deplores the lack of polymer chemistry in the undergraduate curriculum. Others press for more descriptive inorganic chemistry, more communication skills, more computer literacy, and more literacy with respect to information retrieval, and more emphasis on education to produce chemistry teachers. Unfortunately, efforts to encourage introduction of new topics, new areas, new laboratory experience in the undergraduate curriculum too frequently meet with strenuous objection. It is unacceptable to add more material to an already saturated four-year undergraduate curriculum. It is unacceptable to extend the nominal duration of an 
undergraduate program beyond four years. We have to live with a constant volume curriculum. All Science and Engineering disciplines share this problem. Ideas are plentiful as to what should be added to the curriculum, but suggestions as to what to omit are rare, and are rarely accepted.

We are the victims of traditional organizational boundaries imposed on scientific disciplines in our colleges and universities. For example, rarely does a chemistry department discuss its curriculum outside of area categories , typically analytical, physical, inorganic and organic. This impedes change, promotes redundancy, and interferes with optimizing the educational experience. We are imprisoned educationally by outdated boundaries of a discipline, and by textbooks which, by their very organization and absence of alternatives, virtually dictate what is taught. Influencing curricula through organizational change is painstakingly slow and it is clearly a lot easier to clone educational approaches than to mutate them.

Another pitfall should be mentioned. Respected colleagues are on record that science education is too important to be reserved just for scientists. That is to say - science departments are remiss in structuring their programs for scientists alone. What about the non-scientist? The level of education in science for the nonscientist is frighteningly low, both in grade schools and in higher education.

Professional societies, in establishing criteria for accreditation or approval of degree progams, have generally done so according to professional objectives. More recently, however, increasing attention is being given to science education of the nonprofessional and to grade school science education. $A$ committee such as CPT, whose focus is primarily on professional degree programs, can play an indirect but important role in this arena by ensuring high standards in the science education of tomorrow's science teachers. Greater numbers of better-trained teachers would go a long way to alleviate science illiteracy.

\section{REVISED GUIDELINES}

After much thought on the burgeoning applications of chemistry and the many problems previously alluded to, the ACS-CPT has revised its guidelines. Whereas prior to 1988 there was only one degree program described as acceptable to the ACS-CPT as "professional training" for a batchelor's degree chemist, there are now a variety of such programs. They all build on a central foundation of knowledge and basic skills - most commonly attained by the end of the freshman year. They all call for a firm foundation in math and physics and in the core areas of chemistry, namely, inorganic, physical, analytical, organic and bioorganic. Thereafter the programs diverge. They differ only in the nature of the advanced topics taken beyond the core program. Regardless of emphasis, whether in biochemistry, polymer chemistry, chemical education, or standard chemistry, they are all classified as degrees in chemistry. The jury is still out on the value of the revised guidelines, but the intent is to reach out and capture expanding areas of the discipline, and to create more program options and flexibility without sacrificing quality. This is not an invitation to superficiality but an opportunity for the student to focus on one avenue of the discipline and, though the penetration may be small, to focus well. 